\title{
Determination of Discharge Coefficient for both Semicircular and Triangular Labyrinth Weirs
}

\author{
Tara H. Aurahman, Jehan M. Fattah Sheikh Suleimany*, Taban K. Hamad \\ Department of Water Resource Engineering, College of Engineering, Salahaddin University, Erbil, Kurdistan Region, Iraq
}

\begin{abstract}
${ }^{*}$ Corresponding author:
Jehan M. Fattah Sheikh

Suleimany, Department

of Water Resource

Engineering, College of

Engineering, Salahaddin

University, Erbil,

Kurdistan Region, Iraq.

E-mail: jehanmohammed. sheikhsuleimany@su.edu. krd
\end{abstract}

Received: 11 June 2021

Accepted: 27 October 2021

Published: 30 December 2021

DOI

10.25156/pty.v11n2y2021.pp56-64

\section{A B S T R A C T}

A Labyrinth weir is a type of nonlinear weir folded in plan-view, with the ability to pass a large flow at low heads due to an increase in the effective length of the weir crest for a given channel width. The discharge coefficients $\left(C_{d}\right)$ were experimentally determined for both semicircular and triangular labyrinth weirs of varying sidewall angles $(\alpha)$ under free-flow conditions using eight physical models. Dimensional analyses are conducted using the Buckingham $\pi$ theorem to find the dependent and non-dependent variables. A nonlinear empirical equation was developed using (Statistical Package for the Social Sciences 22) software. The findings show that the discharge coefficient decreases with the increase of headwater to $\left(\mathrm{H}_{t} / \mathrm{P}\right)$ for both types of labyrinth weir with different plan forms. It is found that the efficiency of the semicircular and triangular labyrinth is higher than linear weir for $\left(\mathrm{H}_{\mathrm{t}} / P \leq 0.45\right)$ and decreases with increasing the value of $\left(\mathrm{H}_{\mathrm{t}} / \mathrm{P}\right)$ due to interference of flow between the layers in downstream. The obtained results revealed that the discharge coefficient $\left(C_{d}\right)$ values obtained empirically using multivariable power regression and $5^{\text {th }}$ degree polynomial equations considerably agree with the experimental data, for both of the semicircular and triangular labyrinth weirs. Furthermore, the correlation coefficient $R^{2}$ was $(0.9951)$ and $(0.9637)$ using $5^{\text {th }}$ degree polynomial equation, and their values were $(0.9643)$ and $(0.9274)$ using multivariable power regression equation for both semicircular and triangular labyrinth weir models, respectively. The results in the present study compared quite well with the predicted results of the proposed equations obtained by other investigators.

Keywords: Discharge coefficient, Labyrinth weir, Semicircular weir, Triangular weir

\section{INTRODUCTION}

Labyrinth weirs are especially well suited for spillway rehabilitation where dam safety concerns, freeboard limitations, and a revised with larger probable maximum flow have required modification or replacement of the spillway (Crookston, 2010), and (Darvas, 1971).

Labyrinth weirs produce an increase in crest length for a specific channel thickness. Flow over labyrinth weirs is very complex as it is three-dimensional and influenced by many parameters. Therefore, a large number of laboratory tests are needed to determine empirically the influence of the various parameters on the discharge capacity (Schleiss, 2011). The nappes from two weirs placed at an angle with each other will have an impact over a limited length of the weir crest as shown in Figure 1. The effect of the nappe interference is to decrease the discharge. Interference occurs when the jets from the two sidewalls or the apex and the sidewall intersect (Falvey, 2003).

Numerous theoretical and experimental studies have been conducted by many investigators on the hydraulics of labyrinth weirs. (Crookston and Tullis, 2010) used numerical and physical model to calculate the hydraulic performance of labyrinth weir using high water head ratio which is more than one, their results using the computational fluid dynamic method compiled well with discharge that computed from the physical model. (Bilhan et al., 2016) experimentally investigated the discharge capacity of sharp-crested semicircular labyrinth weir and trapezoidal labyrinth weir with sidewall angle equal to $\left(37^{\circ}\right)$, their results show that trapezoidal weir is hydraulically more efficient than semicircular labyrinth and semicircular labyrinth weir have higher discharge coefficient than that of the straight weir. (Ghare et al., (2008) suggest a mathematical model to find the maximum discharge coefficient of trapezoidal labyrinth weir, and methodology for hydraulic design of trapezoidal labyrinth was carried out. It has been calculated that the optimal $C_{d}$ for weir height ratio can be found from Eq. (1). furthermore, the recommended effective crested length of the proposed labyrinth weir can be obtained from equation (2); (Anderson and Tullis, 2012), adopted Eq.(1) to find maximum discharge coefficient of trapezoidal labyrinth weir, and a methodology for hydraulic design of trapezoidal labyrinth weir as shown in Figure 2. Furthermore, they recommended effective crested length of the proposed labyrinth weir by using Eq.(2). (Bilhan 
et al., 2016) were experimentally determined the discharge coefficients for both sharp-crested semi-circular labyrinth weirs and trapezoidal labyrinth weirs of sidewall angle $\left(\alpha=37^{\circ}\right)$. From their experimental study, they found that the discharge coefficient of the circular labyrinth weir is higher than that of the linear weir but lower than that of the trapezoidal weir.

(Azimi and Hakim, 2019) conducted laboratory experiments to study the hydraulics of flow over rectangular labyrinth weirs in both free and submerged flow conditions. They found that the discharge coefficients decreased with increasing the approach velocity and the pool aspect ratio. Semi-empirical formulations were developed to predict the discharge over rectangular labyrinth weirs in free-flow condition.

$Q=\frac{2}{3} C_{d} L \sqrt{2 g} H_{t}^{\frac{3}{2}}$

Where: $\mathrm{Q}$ is the discharge over the labyrinth weir

$\mathrm{C}_{\mathrm{d}}$ is the dimensionless discharge coefficient

$\mathrm{L}$ is the characteristic length (developed crest length)

$\mathrm{g}$ is acceleration due to gravity.

$\mathrm{H}_{\mathrm{t}}$ is the total head over the weir, $\mathrm{H}_{\mathrm{t}}=\mathrm{v}^{2} / 2 \mathrm{~g}+\mathrm{H}$

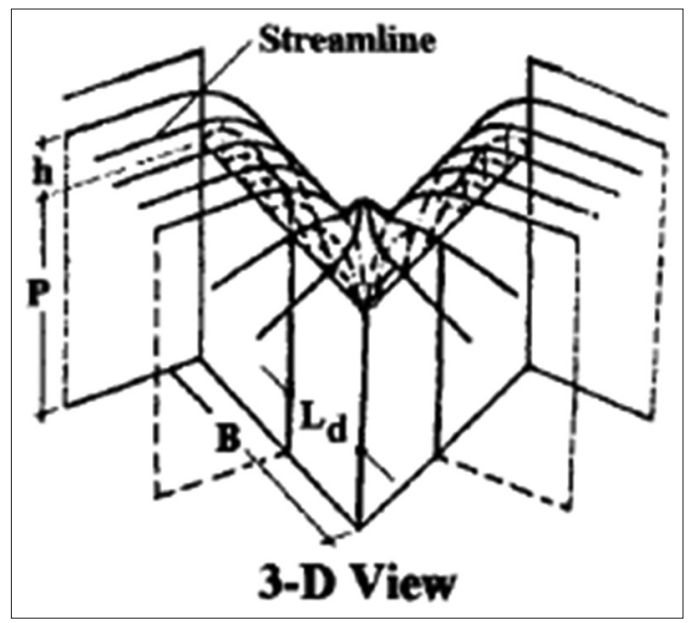

Figure 1: Effect of nappe interference (Falvey, 2003)

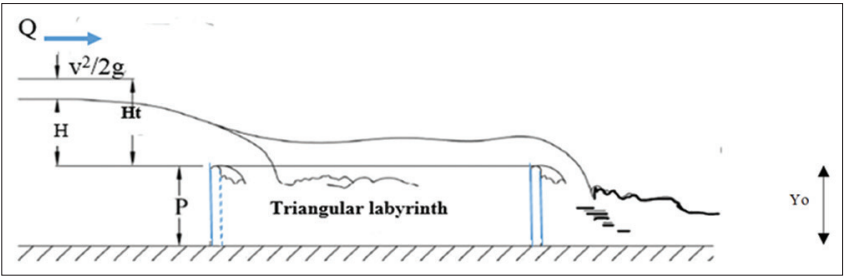

Figure 2: Definition sketch of labyrinth weir under free flow condition
$C_{d}=0.1714 \ln \frac{H_{t}}{P}+0.867$

(Taylor, 1968) presented initial studies on the behavior of labyrinth weirs and compared the hydraulic performance of it with sharp-crested weirs. (Hay and Taylor, 1970) followed up on Taylor's work and developed a design criterion for labyrinth weirs, based on their research finding, they suggested Eq. (3) to estimate the discharge coefficient $C_{d}$ of labyrinth weirs.

$C_{d}=3.22+0.4\left(\frac{H_{t}}{p}\right)$

\section{MATERIALS AND METHODS}

\section{Theoretical Discharge (Q) and Total Head over the Weir $\left(\mathrm{H}_{\mathrm{t}}\right)$ Relationships}

Eq. (1) for flow over labyrinth weir was used, as explained earlier in this study.

\section{Theoretical $\left(\mathrm{C}_{\mathrm{d}}\right)$ with $\left(\mathrm{H}_{\mathrm{t}} / \mathrm{P}\right)$ Relationships}

The headwater ratio $\left(\mathrm{H}_{\mathrm{t}} / \mathrm{P}\right)$ is the total head $\left(\mathrm{H}_{\mathrm{t}}\right)$ on the weir divided by the weir height $(\mathrm{P})$. It's recommended taking the maximum headwater ratio $\left(\mathrm{H}_{\mathrm{t}} / \mathrm{p}\right)=0.9$ for triangular labyrinth weir form (Tullis et al., 1995). Eq. (4) designated as the Rehbock formula proposed by (Subramanya, 1972) was used forth analysis of the free flow over the triangular and semicircular plan form labyrinth weirs and for calculating the discharge coefficient $\left(\mathrm{C}_{\mathrm{d}}\right)$.

$C_{d}=0.611+0.083\left(\frac{H_{t}}{P}\right)$

Impact of Magnification Ratio (L/W) on Discharge (Q) The magnification ratio is the length of the labyrinth crest length divided by width of the weir (L/W). It represents the theoretical maximum magnification of discharge when compared with a linear weir (Crookston, 2010). For the triangular labyrinth, the sidewall angle $(\alpha)$ and the magnification ratio are interrelated. The angle is given by Eq. (5) as demonstrated in Figure 3.

$\alpha=\sin ^{-1}\left(\frac{W}{2} \times \mathrm{B}\right)$

Where B = Side length of the semicircular labyrinth weir as shown in Figure 3.

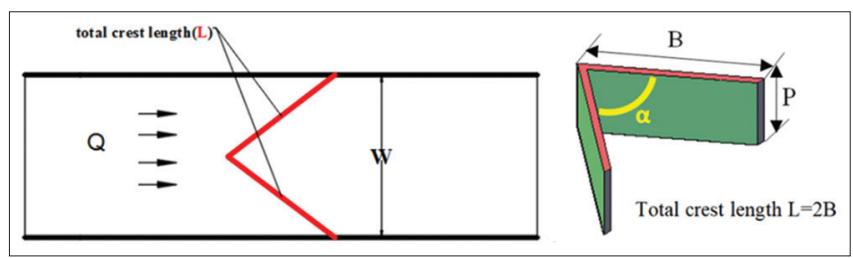

Figure 3: Definition sketch of triangular labyrinth weir 
Effect of the Vertical Aspect Ratio (W/P) on the Hydraulic Performance of Labyrinth Weir

The vertical aspect ratio $(\mathrm{W} / \mathrm{P})$ is the width of a weir divided by the weir height (Hay and Taylor, 1970) show that the aspect ratio has no significance if it's $>2$. (Taylor, 1968) recommends that to minimize the effect of nappe interference, the $(\mathrm{W} / \mathrm{P})$ should be larger than 2 .

\section{Dimensional Analysis}

For triangular labyrinth weir

The variables that might have an impact on the discharge of the triangular labyrinth weir are height of the weir (p), width of triangular labyrinth weir (W), head over the triangular weir $(\mathrm{H})$, total development crest length $(\mathrm{L})$, side wall angle $(\alpha)$, thickness of the wall $(\mathrm{t}=0.8 \mathrm{~cm})$, surface tension $(\sigma)$, viscosity $(\mu)$, mass density $(\rho)$, and gravitational acceleration $(\mathrm{g})$ as shown in Figure 3. A general functional equation for these variables can be written as:

$$
Q=f(\rho, g, \mu, \sigma, V, H, L, P, W, \alpha)
$$

Using $\pi$ theorem (Chow, 1959) the following dimensionless terms were carried out from Eq. (6) as presented in Eq. 7.

$$
\frac{Q}{\sqrt{g} H^{\frac{5}{2}}}=\varphi\left[\operatorname{Re}, W e, \frac{H}{L}, \frac{H}{W}, F r, \frac{H}{P}, \alpha\right]
$$

It's recommended that the flow condition is subcritical; therefore Froude, Reynolds and Weber numbers can be negligible. The most important geometrical parameter that influence discharge coefficient is presented in Eq. (8)

$C_{d}=\varphi\left[\frac{L}{W}, \frac{H}{P}\right]$

\section{For semicircular labyrinth weir}

The discharge over the semicircular labyrinth depends on the following variables:

Height of semicircular labyrinth weir (P), width of the semicircular labyrinth weir (W), total crest length of labyrinth weir (L), flow over the labyrinth weir $(\mathrm{H})$, constant wall thickness $(t=0.8 \mathrm{~cm})$, radius of semi-circle $(\mathrm{R})$ as shown in Figure 4.

$Q=(R, H, L, P, W)$

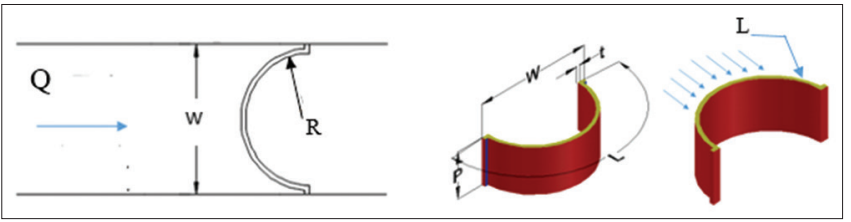

Figure 4: Definition sketch of semicircular labyrinth weir
$C_{d}=\varphi\left[\frac{H}{P}, \frac{W}{P}, \frac{R}{W}\right]$

\section{Experimental Work and Setup}

The experiments performed at the Laboratory of Hydraulic, Department of Civil Engineering. Salahaddin University. The experiments were performed on a smooth toughened glass sided and smooth bed steel plate channel of $3 \mathrm{~m}$ working length. The flume cross-sectional area is $25 \mathrm{~cm}$ wide and $30 \mathrm{~cm}$ deep. The longitudinal slope of the Flume can be adjusted mechanically by two hydraulic jacks raised and lowered manually to establish the required slope.

Water supplied to the flume from an underground concrete storage tank of internal dimensions $(7.5 \mathrm{~m}$ length, $2.5 \mathrm{~m}$ width, and $1.0 \mathrm{~m}$ depth). Water drawn from the underground storage tank by an electrically driven centrifugal pump through a 6-inch diameter Steel pipe to the overhead tank providing a total discharge of $(50 \mathrm{l} / \mathrm{s})$. The discharge in the flume was measured by means of a $\mathrm{V}$-notch weir located at the end of the overhead tank as presented in Eq. (11) (Mohammed, 2010)

$Q_{v}=0.0195 H_{v}^{2.398}$

Where:

Q: Discharge of the channel in liter/sec, and

$H_{v}$ : Head of water above the $\mathrm{V}$-notch weir in $\mathrm{cm}$.

Three model configurations of triangular labyrinth weir and five model configurations of semicircular labyrinth weir and a linear weir were made from special plastic called acrylic; the models were fixed at distance of $2.5 \mathrm{~m}$ from the channel inlet. Based on $6^{\circ} \leq$ sidewall angles $\leq 35^{\circ}$ (Crookston and Tullis, 2010) and side wall $=37^{\circ}$ (Bilhan et al., 2016), the model of triangular plan form constructed with various sidewall angles $(\alpha) 37^{\circ}, 30^{\circ}$, and $23^{\circ}$ respectively with constant height $(\mathrm{P})$ as shown in Figures 5 and 6.

The performance of the semicircular labyrinth weir can be examined well if the radius (R) of the semicircle will be various, as the crest length will be changed by changing the radius (Bilhan et al., 2016), The models of semicircular plan form weir performed with three different heights and different radius as shown in Tables 1 and 2, accordingly. Each flow state consists of a number of runs. For each run, the depth of water above the $\mathrm{V}$-notch weir $\left(\mathrm{H}_{\mathrm{v}}\right)$ and the corresponding uniform water depth in the canal upstream of the tested model $\left(\mathrm{Y}_{\alpha}\right)$ were measured.

\section{RESULTS AND DISCUSSION}

\section{For Triangular Labyrinth Weir}

Variation of $\left(H_{f} / P\right)$ with $\left(C_{d}\right)$ for different values of $(\alpha)$ Figure 7 shows the variation of headwater ratio $\left(H_{t} / \mathrm{P}\right)$ with the coefficient of discharge $\left(\mathrm{C}_{\mathrm{d}}\right)$ for different 


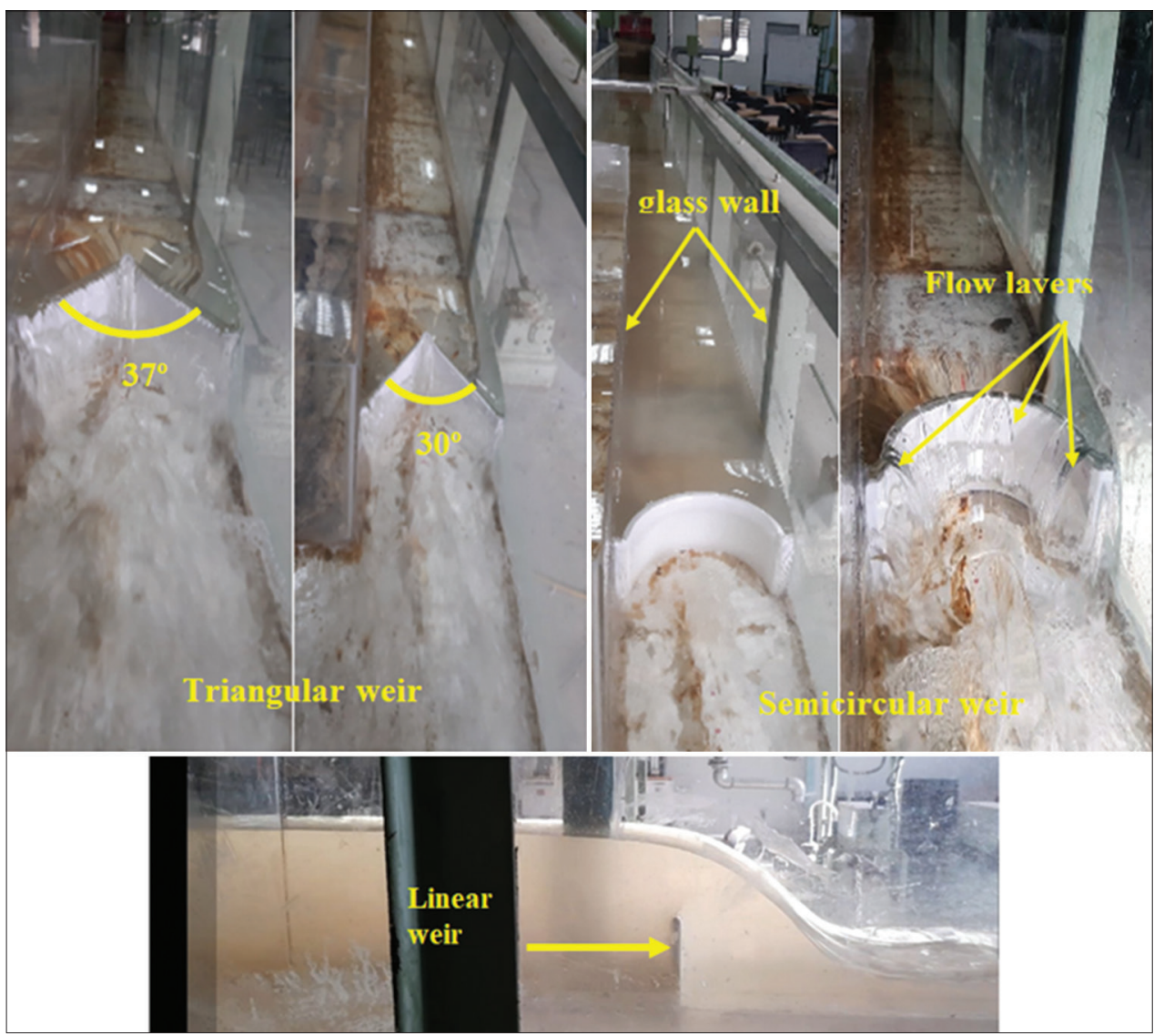

Figure 5: Images for the models of semicircular and triangular labyrinth weir, and linear crested weir under free flow condition
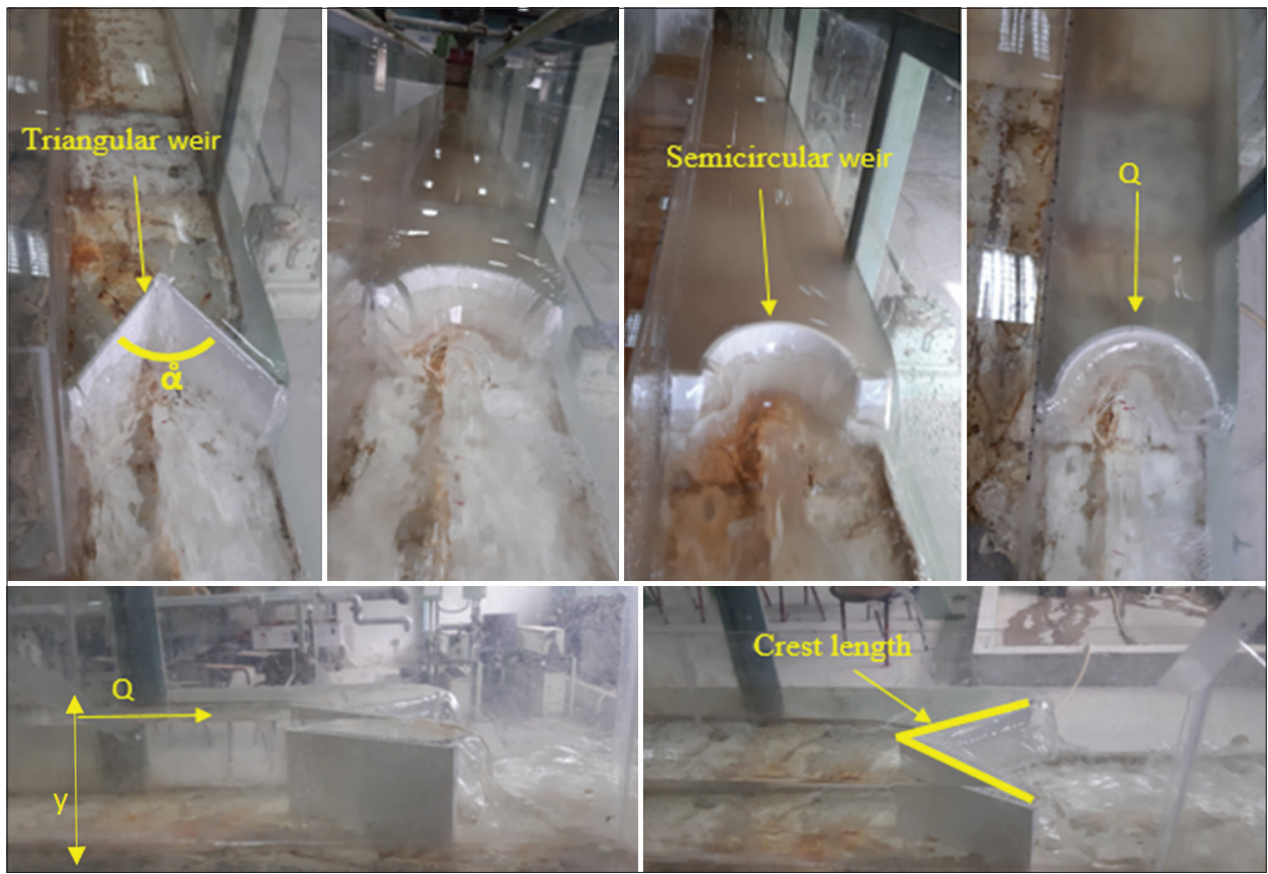

Figure 6: Images for experimental lay out of different plan form of labyrinth weir installed in laboratory channel

sidewall angles $(\alpha)$. The results indicate that the discharge coefficient $\left(\mathrm{C}_{\mathrm{d}}\right)$ increased as the water head ratio $\left(\mathrm{H}_{\mathrm{t}} / \mathrm{P}\right)$ decreased and the sidewall angles $(\alpha)$ increased. Due to interference of overflowing layer for high value of $\left(\mathrm{H}_{\mathrm{t}} / \mathrm{P}\right)$, the triangular plan form with $37^{\circ}$ has more effectiveness. 
Table 1: Experimental data for semicircular labyrinth weir models

\begin{tabular}{|c|c|c|c|c|c|c|}
\hline Model no. & Height $(P)$ in $\mathrm{cm}$ & $\begin{array}{c}R \text { (radius of } \\
\text { semicircle in } \mathrm{cm})\end{array}$ & Run no. & $H_{t} / P$ & $Q_{v}=0.0195 H_{v}^{2.398(V s)}$ & $\mathrm{C}_{\mathrm{d}}$ \\
\hline 1 & 10 & 9 & $1-9$ & $0.16-0.7$ & $1.603-11.983$ & $0.62-0.77$ \\
\hline 2 & 10 & 10 & $10-19$ & $0.42-1.015$ & $5.734-17.465$ & $0.50-0.63$ \\
\hline 3 & 10 & 11 & $20-29$ & $0.31-0.91$ & $4.311-17.159$ & $0.56-0.70$ \\
\hline 4 & 12 & 11 & $30-40$ & $0.21-0.85$ & $3.443-19.722$ & $0.54-0.73$ \\
\hline 5 & 8 & 11 & $41-49$ & $0.53-0.64$ & 4.208-13.309 & $0.53-0.64$ \\
\hline
\end{tabular}

Table 2: Experimental data for triangular weir models

\begin{tabular}{lcccccc} 
Model no. & $\alpha$ & L/W & Run no. & $H_{t} / P$ & $\mathbf{Q}_{v}$ & $C_{d}$ \\
\hline 6 & $37^{\circ}$ & 0.415 & $50-59$ & $0.324-0.942$ & $4.817-18.746$ & $0.52-0.67$ \\
7 & $30^{\circ}$ & 0.5 & $60-69$ & $0.265-1.013$ & $4.421-22.452$ & $0.47-0.69$ \\
8 & $23^{\circ}$ & 0.639 & $70-77$ & $0.217-0.773$ & $5.644-19.268$ & $0.47-0.66$ \\
Linear weir & $90^{\circ}$ & 1 & $78-87$ & $0.465-1.097$ & $4.82-18.75$ & $0.65-0.7$ \\
\hline
\end{tabular}

Impact of magnification ratio (L/W) on discharge (Q) Because the discharge coefficient decreases with increasing head, labyrinth weirs have the greatest application where the head is small. Figure 8 demonstrates the variation of discharge capacity with total $\left(\mathrm{H}_{t}\right)$ with different value of magnification ratio (L/W), in which indicated that the triangular labyrinth weir with higher value of $(\mathrm{L} / \mathrm{W})$ gives higher value of discharge capacity It means that with increasing the value of $(\mathrm{L} / \mathrm{W})$ the hydraulic performance of labyrinth weir with triangular plan form increase, in addition, due to increased crest length of this weir more discharges of water will flow with low head.

\section{For Semicircular Labyrinth Weir Variation of $\left(H_{t}\right)$ with $(Q)$ and $(W / P)$}

Figure 9 indicates that increasing the aspect ratio $(\mathrm{W} / \mathrm{P})$, discharge (q) will be decreased this result confirms the findings of (Hay and Taylor, 1970) that labyrinth semicircular weirs performance increased for value of $(\mathrm{W} / \mathrm{P})<2$.

\section{Variation of $\left(H_{t}\right)$ with $\left(C_{d}\right)$ and $(W / P)$}

Figure 10 shows that increasing $\left(\mathrm{H}_{\mathrm{t}} / \mathrm{P}\right)$ will decrease $\left(\mathrm{C}_{\mathrm{d}}\right)$, and increasing $(\mathrm{W} / \mathrm{P})$ will increase $\left(\mathrm{C}_{\mathrm{d}}\right)$.

\section{Empirical Equations}

Nonlinear Regression equation developed in Statistical Package for the Social Sciences (SPSS) 22 program to predict the discharge coefficient $\left(\mathrm{C}_{\mathrm{d}}\right)$ for each models of semicircular labyrinth weir and triangular labyrinth weir as follows:

\section{For triangular labyrinth weir}

Table 3 shows the estimated coefficient of discharge $\left(\mathrm{C}_{\mathrm{d}}\right)$ using (SPSS 22) software and $5^{\text {th }}$ degree polynomial equation with correlation coefficient $R^{2}=0.99$ for all sidewall angles $(\alpha)$. All $\left(\mathrm{C}_{\mathrm{d}}\right)$ relations were in terms of

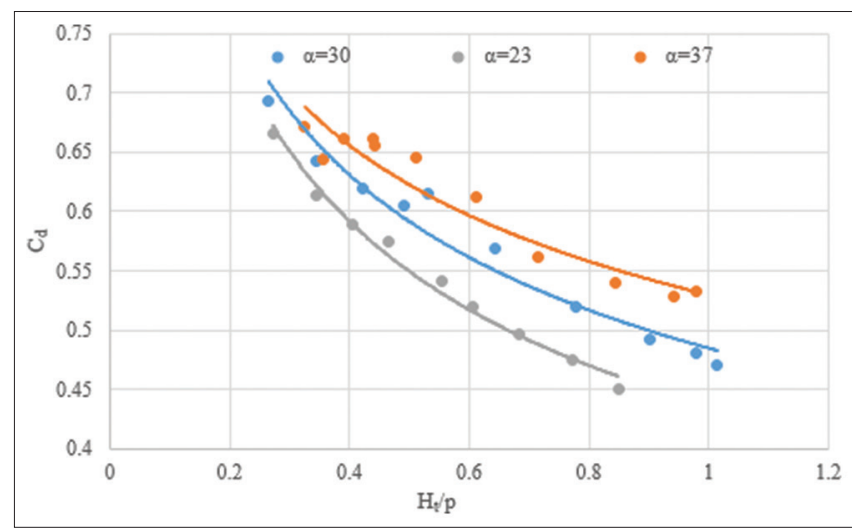

Figure 7: Variation of $\left(C_{d}\right)$ with $\left(H_{t} / P\right)$ for different values of $(\alpha)$

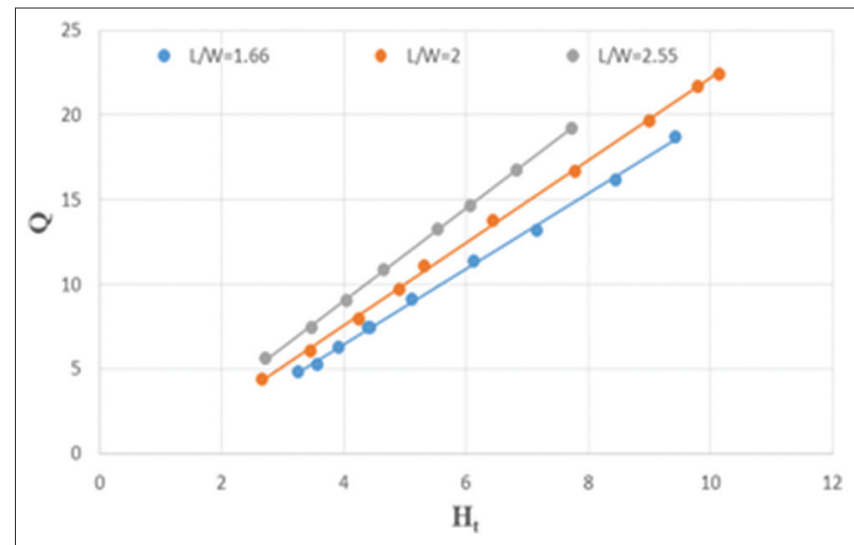

Figure 8: Impact of (L/W) on (Q)

$\left(\mathrm{H}_{\mathrm{t}} / \mathrm{P}\right)$ for each model which gives the best fit (very high correlation coefficient) as shown in Eq. (12), Eq. (13), and Eq. (14).

Based on Eq. (8) with correlation coefficient $\mathrm{R}^{2}=0.96$. Multivariable power regression was created to relate $\left(\mathrm{C}_{\mathrm{d}}\right)$ and $\left(\mathrm{H}_{\mathrm{t}} / \mathrm{P}\right)$ in an empirical relation which was in terms of $\left(\mathrm{H}_{\mathrm{t}} / \mathrm{p}\right),(\mathrm{L} / \mathrm{W})$ as shown in Eq. (15) 
Table 3: Different $(C d)$ Equations using $5^{\text {th }}$ degree polynomial equations Side wall angle $(\alpha) \quad$ Coefficients of discharge $\left(C_{d}\right)$ using $5^{\text {th }}$ degree polynomial equations

$37^{\circ}$

$$
C_{d}=3.64-44.19\left(\frac{H_{t}}{P}\right)^{5}+140.207\left(\frac{H_{t}}{p}\right)^{4}-170.856\left(\frac{H_{t}}{p}\right)^{3}+99.414\left(\frac{H_{t}}{p}\right)^{2} 27.742\left(\frac{H_{t}}{p}\right)(12)
$$

$30^{\circ}$

$$
C_{d}=2.333-16.845\left(\frac{H_{t}}{p}\right)^{5}+57.904\left(\frac{H_{t}}{p}\right)^{4}-76.335\left(\frac{H_{t}}{p}\right)^{3}+47.923\left(\frac{H_{t}}{p}\right)^{2}-14.506\left(\frac{H_{t}}{p}\right)
$$

$23^{\circ}$

$$
C_{d}=2.798-51.479\left(\frac{H_{t}}{p}\right)^{5}+140.72\left(\frac{H_{t}}{p}\right)^{4}-150.902\left(\frac{H_{t}}{p}\right)^{3}+79.35\left(\frac{H_{t}}{p}\right)^{2}-20.8\left(\frac{H_{t}}{p}\right)(14)
$$

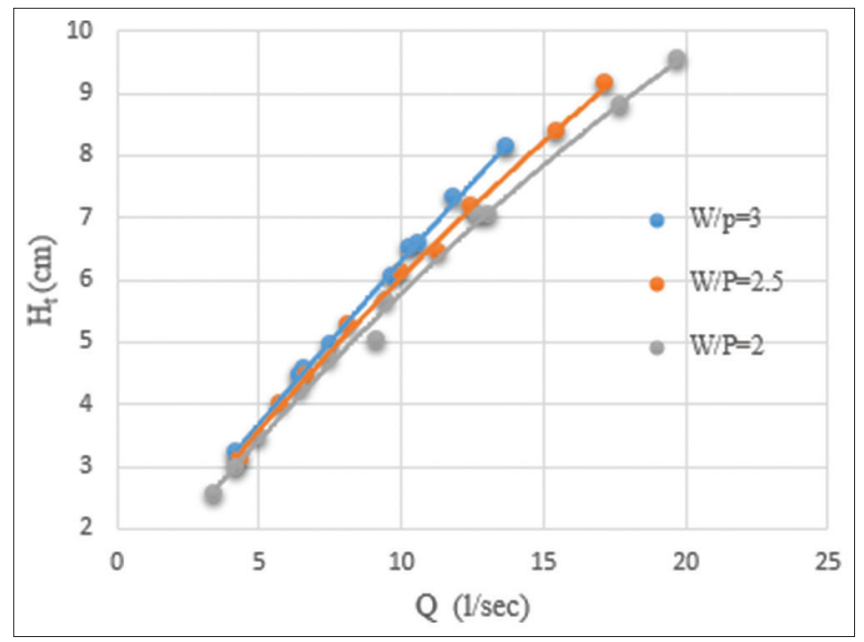

Figure 9: Variation of $(q)$ with $\left(H_{t}\right)$ for different values of (W/P)

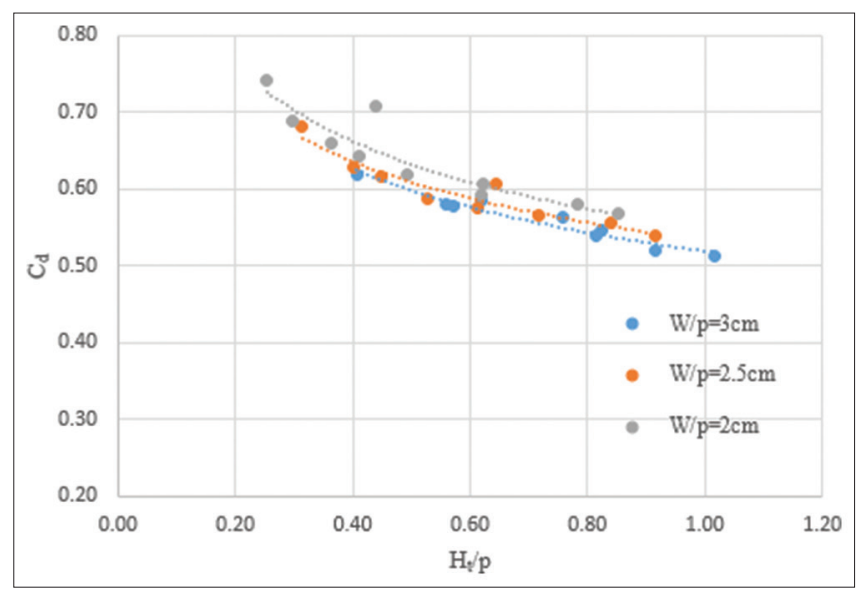

Figure 10: Variation of $\left(C_{d}\right)$ with $\left(H_{t} / p\right)$ for different values of $(W / P)$

$$
\begin{aligned}
& C_{d}=0.964-0.124\left(\frac{H_{t}}{p}\right)^{3}+0.355\left(\frac{H_{t}}{p}\right)^{2} \\
& -0.57\left(\frac{H_{t}}{p}\right)-0.001\left(\frac{L}{W}\right)^{2}-0.074\left(\frac{L}{w}\right)
\end{aligned}
$$

\section{For semicircular weir}

Table 4 demonstrates different coefficients of discharge $\left(\mathrm{C}_{\mathrm{d}}\right)$ obtained by using (SPSS 22) software and $5^{\text {th }}$ degree polynomial equation with correlation $\mathrm{R}^{2}=0.99$ for all semicircular plan form models. All $\left(\mathrm{C}_{\mathrm{d}}\right)$ relations were in terms of $\left(\mathrm{H}_{\mathrm{t}} / \mathrm{P}\right)$ for each models which gives the best fit (very high correlation coefficient) as shown in Eq. (16), Eq. (17), Eq. (18), Eq. (19), and Eq. (20).

Based on Eq. (10) with correlation coefficient $\mathrm{R}^{2}=0.927$, multivariable nonlinear regression was used to correlate $\left(\mathrm{C}_{\mathrm{d}}\right)$ and $\left(\mathrm{H}_{\mathrm{t}} / \mathrm{P}\right)$ in an empirical relation. The $\left(\mathrm{C}_{\mathrm{d}}\right)$ relations were in terms of $\left(\mathrm{H}_{\mathrm{t}} / \mathrm{P}\right),(\mathrm{R} / \mathrm{W})$, and $(\mathrm{W} / \mathrm{P})$ as shown in Eq. (21)

$$
\begin{aligned}
& C_{d}=3.41-1.906\left(\frac{H_{t}}{P}\right)^{4}+4.526\left(\frac{H_{t}}{P}\right)^{3}- \\
& 3.593\left(\frac{H_{t}}{P}\right)^{2}+0.844\left(\frac{H_{t}}{P}\right)-0.249\left(\frac{W}{P}\right)^{2}+ \\
& 1.316\left(\frac{W}{P}\right)+29.755\left(\frac{R}{W}\right)^{2}-23.355\left(\frac{R}{W}\right)
\end{aligned}
$$

Comparison of $\left(\mathrm{C}_{\mathrm{d}}\right)$ predicted from nonlinear regression equations to $\left(C_{d}\right)$ experimentally observed.

\section{For Triangular Labyrinth Weir Models}

Figure 11 demonstrates the comparison of $\left(\mathrm{C}_{d}\right)$ predicted with $\left(C_{d}\right)$ observed using $5^{\text {th }}$ degree polynomial equation. Figure 12 shows the relation between predicted $\left(C_{d}\right)$ obtained using multivariable power regression equation and observed $\left(\mathrm{C}_{\mathrm{d}}\right)$ obtained experimentally for triangular weir.

It is observed that both $5^{\text {th }}$ degree polynomial and multivariable power regression equations are in excellent agreement for labyrinth triangular weirs.

\section{For Semicircular Labyrinth Weir Models}

Figure 13 shows relation between Predicted $\left(\mathrm{C}_{\mathrm{d}}\right)$ obtained from $5^{\text {th }}$ degree polynomial equation and 


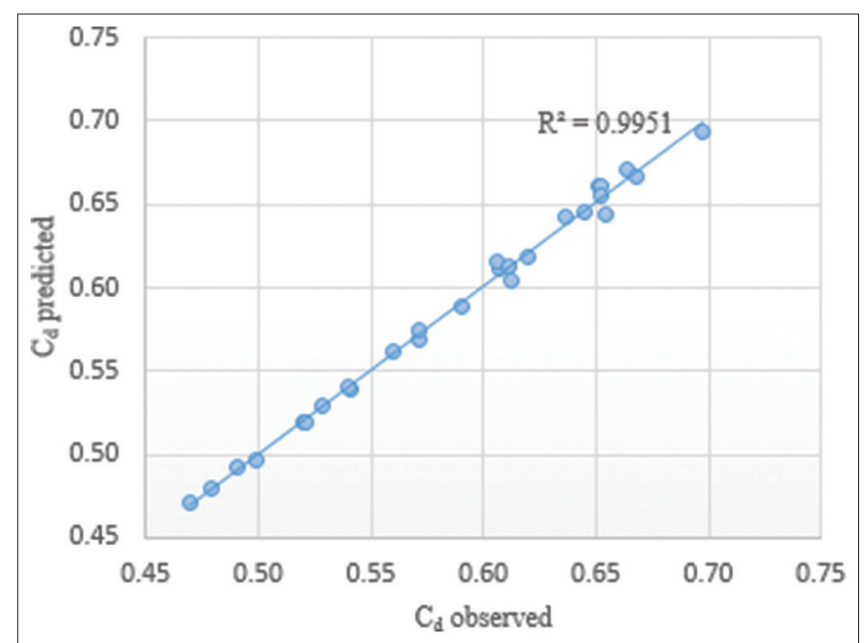

Figure 11: Comparison of $\left(C_{d}\right)$ predicted to $\left(C_{d}\right)$ observed using $5^{\text {th }}$ degree polynomial equation

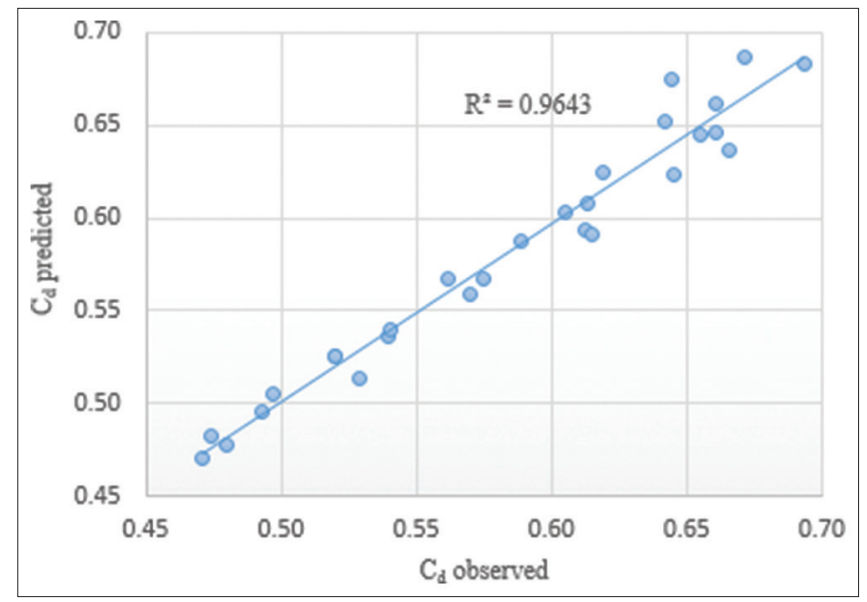

Figure 12: Comparison of $\left(C_{d}\right)$ predicted to $\left(C_{d}\right)$ observed using multivariable power regression

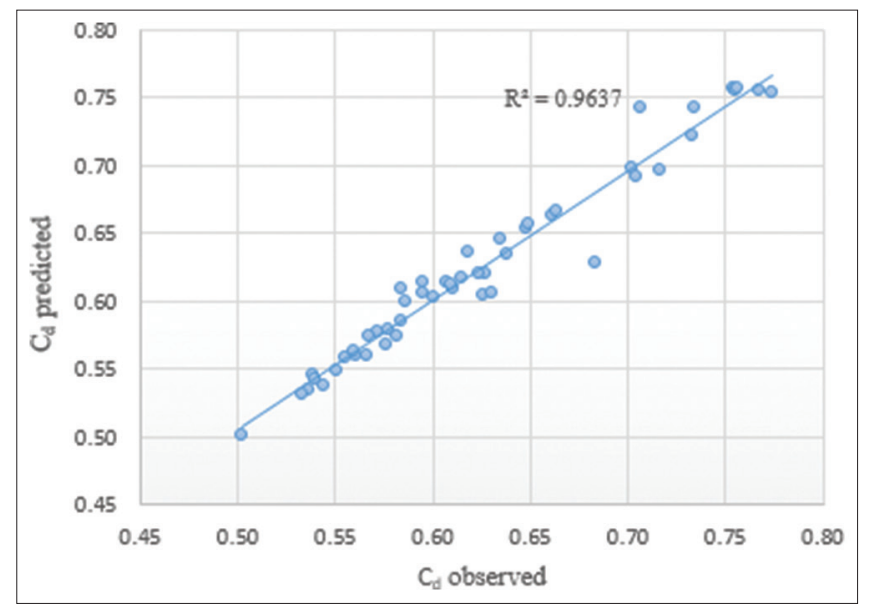

Figure 13:Variation ofpredicted $\left(C_{d}\right)$ using $5^{\text {th }}$ degree polynomial equation and experimentally observed $\left(C_{d}\right)$

observed $\left(\mathrm{C}_{\mathrm{d}}\right)$ obtained from experiment results. Figure 14 shows a comparison between $\left(C_{d}\right)$ value

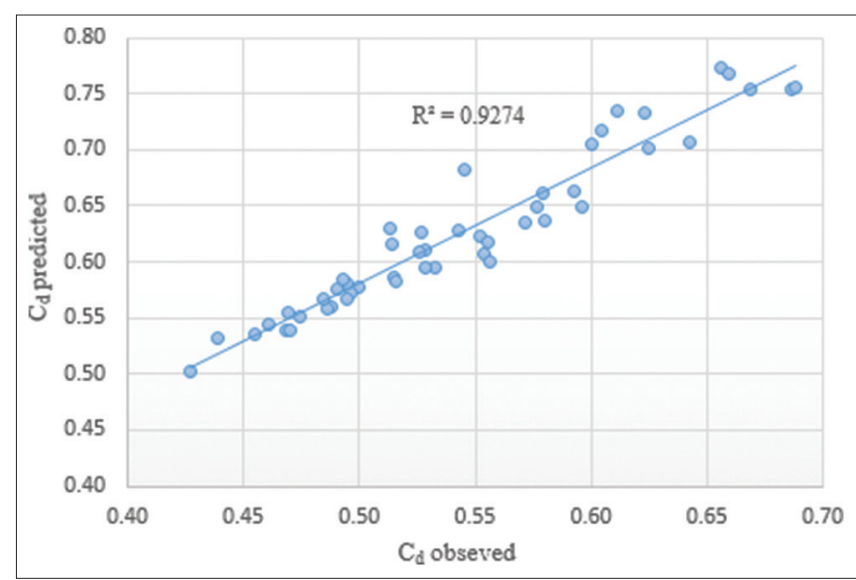

Figure 14: Variation of predicted $\left(C_{d}\right)$ from multivariable power regression equation and experimental $\left(C_{d}\right)$

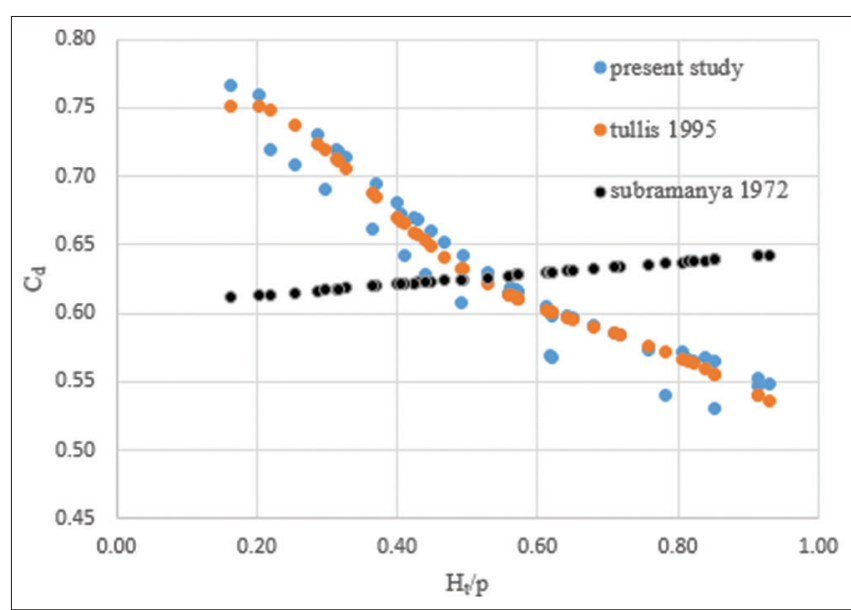

Figure 15: Variation of $\left(C_{d}\right)$ with $\left(H_{t} / P\right)$ for the present study results compared to those of previous investigators for labyrinth weir

predicted by multivariable regression equation and $\left(\mathrm{C}_{\mathrm{d}}\right)$ observed experimentally.

The results indicate that both $5^{\text {th }}$ degree polynomial and multivariable power regression equations are in excellent agreement with the results obtained experimentally for the semicircular labyrinth weir.

\section{Comparison of $\left(C_{d}\right)$ predicted to $\left(C_{d}\right)$ observed from} other studies

Most of the previous works were done on hydraulic characteristics of flow passing over labyrinth weir with different plan forms. Figure 15 shows the comparison of the present study results for labyrinth weir with different plan forms and linear weir with other investigators. It is indicated that the present study results lay within the results obtained by (Tullis et al., 1995). Also, the results do not comply with (Subramanya, 1972) findings. Because he used a linear weir. 
Table 4: Varies coefficients of discharge $(\mathrm{Cd})$ using $5^{\text {th }}$ degree polynomial equation

No. of models

Coefficients of discharge $\left(C_{d}\right)$

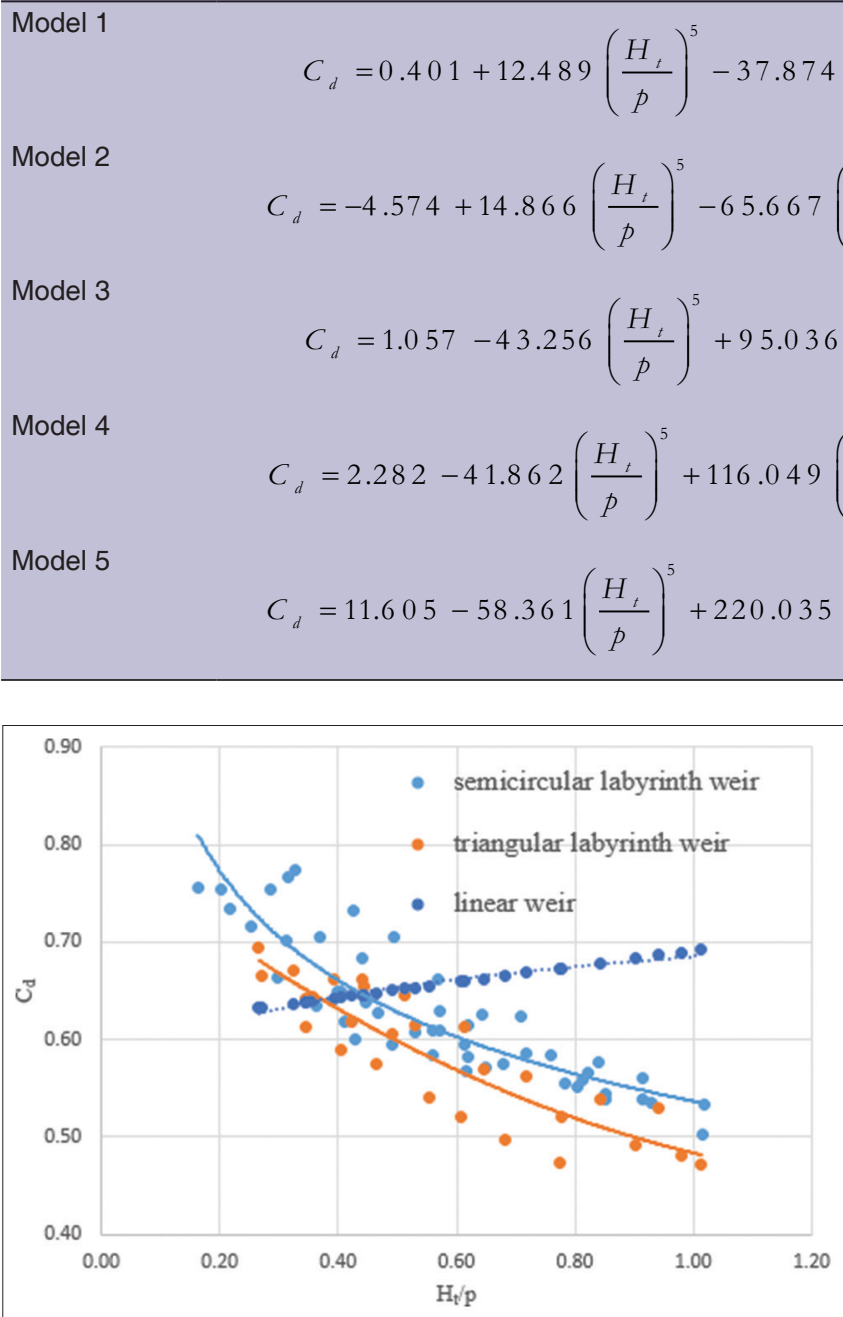

Figure 16: Variation of $C_{d}$ with $H_{t} / P$ for labyrinth and linear weirs

\section{Comparisons between triangular and semicircular labyrinth weirs with linear weirs}

Figure 16 shows the comparison between triangular and semicircular plan form with linear weirs. The results show that the labyrinth weirs with semicircular form give higher value of discharge coefficient by amount of $(7 \%)$. The efficiency of semicircular and triangular labyrinth form is higher than linear weir for $\left(\mathrm{H}_{\mathrm{t}} / \mathrm{P} \leq 0.45\right)$, and decrease with increasing the value of $\left(\mathrm{H}_{\mathrm{t}} / \mathrm{P}\right)$ due to interference of flow between the layer in down stream.

\section{CONCLUSIONS}

The experimental investigation was performed to study the discharge capacity of the different plan forms of labyrinth weir under free-flow condition in a rectangular channel. The key messages of this study are the following:

1. For triangular labyrinth weir, the discharge coefficient $\left(C_{d}\right)$ decreases with a decrease of sidewall angle $(\alpha)$ the triangular weir with $\alpha=37^{\circ}$ gave a higher discharge coefficient $\left(C_{d}\right)$ than the triangular weir with $\alpha=23^{\circ}$

2. The discharge coefficient decreases $\left(\mathrm{C}_{\mathrm{d}}\right)$ with increasing headwater ratio $\left(\mathrm{H}_{\mathrm{t}} / \mathrm{P}\right)$ for both labyrinth and semicircular weir models

3. The efficiency of the semicircular and triangular labyrinth is higher than linear weir for $\left(\mathrm{H}_{\mathrm{t}} / P \leq 0.45\right)$ and decreases with increasing the value of $\left(\mathrm{H}_{\mathrm{t}} / \mathrm{P}\right)$ due to interference of flow between the layers in downstream

4. The aspect ratio $(\mathrm{W} / \mathrm{P})$ has an effect on the performance of the labyrinth weir

5. The empirical equations predicting the discharge coefficient $\left(\mathrm{C}_{\mathrm{d}}\right)$ of the semicircular and triangular labyrinth weirs were developed. According to the suggested equation $\left(\mathrm{C}_{\mathrm{d}}\right)$ depends on dimensionless parameter $\left(\mathrm{H}_{\mathrm{t}} / \mathrm{p}\right)$. In addition, experiment results in this study indicates that the discharge coefficient $\left(\mathrm{C}_{\mathrm{d}}\right)$ depends on dimensionless parameters, which are the ratios of $\left.\left(\mathrm{H}_{\mathrm{t}} / \mathrm{P}\right), \mathrm{L} / \mathrm{W}\right)\left(\mathrm{H}_{\mathrm{t}} / \mathrm{P}\right),(\mathrm{R} / \mathrm{W})$, and $(\mathrm{W} / \mathrm{P})$ for the triangular and semicircular labyrinth weirs respectively

6. The empirically obtained equations for discharge coefficient $\left(\mathrm{C}_{\mathrm{d}}\right)$ agree considerably with the experimental data for the semicircular and labyrinth weir models. Furthermore, the correlation coefficient $\mathrm{R}^{2}$ was (0.9951) and $(0.9637)$ using $5^{\text {th }}$ degree polynomial equation, and their values were (0.9643) and (0.9274) using multivariable power regression for the semicircular and labyrinth weir models respectively

7. The results in the present study compared well with (Tullis et al., 1995).

\section{REFERENCES}

Anderson, R. M. and B. P. Tullis. 2012. Comparison of piano key and rectangular labyrinth weir hydraulics. J. Hydraulic Eng. 138(4): 358-361. 
Azimi, A. H. and S. S. Hakim. 2019. Hydraulics of flow over rectangular labyrinth weirs. Irrig. Sci. 37(2): 183-193.

Bilhan, O., E. Emiroglu and C. J. Miller. 2016. Experimental investigation of discharge capacity of labyrinth weirs with and without nappe breakers. World J. Mech. 6(6): 207-221.

Chow, V. T. 1959. Open-Channel Hydraulics. McGraw-Hill Civil Engineering Series, New York, United States.

Crookston, B. and B. P. Tullis. 2010, November.Hydraulic performance of labyrinth weirs. In: Janssen, $\mathrm{R}$. and $\mathrm{H}$. Chanson, editors. Proceedings $3^{\text {rd }}$ International Junior Researcher and Engineer Workshop on Hydraulic Structures, Edimburg. Hydraulic Model Report No. CH80/10. University of Queensland, Brisbane. p39-46.

Crookston, B. M. 2010. Labyrinth Weirs, Ph. D. Thesis. Utah State University, United States.

Crookston, B. M. and B. Tullis. 2010. Labyrinth Weirs, Hydraulic Structures. p59.

Darvas, L. A. 1971. Discussion of "Performance and design of labyrinth weirs". J. Hydraul. Eng. Div. 97(8): 1246-1251.

Falvey, H. T. 2003, January. Hydraulic Design of Labyrinth Weirs. The American Society of Civil Engineers, Reston, Virginia, United States.
Ghare, A. D., V. A. Mhaisalkar and P. D. Porey. 2008.An approach to optimal design of trapezoidal labyrinth weirs. World Appl. Sci. J. 3(6): 934-938.

Hay, N. and G. Taylor. 1970. Performance and design of labyrinth weirs. J. Hydraul. Eng. Div. 96(11): 2337-2357.

Matos, J. and H. Chanson. 2006. Hydraulic Structures: A Challenge to Engineers and Researchers. Proceedings of the International Junior Researcher and Engineer Workshop on Hydraulic Structures.

Mohammed, O. K. 2010. Flow Characteristics through Pipe Culvert Combined with Broad Crested Weir (MSc Thesis, College of Engineering Salahaddin University Erbil).

Schleiss, A. J. 2011. From labyrinth to piano key weirs: A historical review. In: Proceedings of the International Conference Labyrinth and Piano Key Weirs. p3-15.

Subramanya, K. 1972. Rapidly varied flow-2. J. Hydraul. Eng. 98(1): 295.

Taylor, G. 1968. The Performance of Labyrinth Weirs, Ph. D. Thesis. University of Nottingham, United Kingdom.

Tullis, J. P., N. Amanian and D. Waldron. 1995. Design of labyrinth spillways. J. Hydraul. Eng. 121(3): 247-255. 